\title{
Assessment of Using Cosmetics Containing Hydroquinone among Sudanese Women
}

\author{
H. M. Osman 1*, M. E. Shayoub², Munzir M. E. Ahmed', E. M. Babiker ${ }^{4}$ \\ ${ }^{1}$ Department of Biochemistry, Faculty of Pharmacy, University of National Ribat, Khartoum, Sudan \\ ${ }^{2}$ Department of Pharmaceutics, Faculty of Pharmacy, University of Khartoum, Khartoum, Sudan \\ ${ }^{3}$ Department of Biochemistry, Faculty of Medicine, AL-Gadarif University, Gadarif, Sudan \\ ${ }^{4}$ Department of Zoology, Faculty of Sciences, University of Khartoum, Khartoum, Sudan \\ Email: hisham1212ribat@yahoo.com, profshayoub51@gmail.com, munzirhmd@hotmail.com, \\ embabiker@uofk.edu
}

Received 3 April 2015; accepted 23 May 2015; published 28 May 2015

Copyright (C) 2015 by authors and Scientific Research Publishing Inc.

This work is licensed under the Creative Commons Attribution International License (CC BY). http://creativecommons.org/licenses/by/4.0/

c) (i) Open Access

\begin{abstract}
Many countries in the world wide banned hydroquinone in cosmetics skin lightening but it is still used in most of Africa countries, including Sudan. Few studies were carried out on the side effect of hydroquinone on Sudanese women. Therefore, the present study was carried out in Khartoum state in April to May/2014 to assess the awareness of Sudanese women about using hydroquinone and its probable risks. The results revealed that, highly using cosmetics containing hydroquinone by women aged between 20 - 29 years $(78.3 \%)$ as well as by those classified as single $(69.6 \%)$. The results also showed that the highest percentage of women was using it during evening $(81.2 \%)$ and a high percentage of them was using it for skin lightening $(65.2 \%)$, followed by elimination acne $(20.3 \%)$ and about $10.1 \%$ for both skin lightening and elimination of acne and very little $\mathbf{( 4 . 3 \% )}$ for freckle elimination. Moreover, the results showed a very high percentage of women (94.2\%) used the chemical without being prescribed by doctors and about (85.5\%) of them didn't know its nature and risks on human health. Consequently, $(50.7 \%)$ of women have had sides effects, (44.9\%) used more than one and (44.1\%) used it regularly. In addition, the results revealed that a wide range of products of this chemical was available in local market with amalico (34.8\%) being highly used. The study can conclude that the awareness of Sudanese women about this compound was poor and needs to be raised by health authorities.
\end{abstract}

\section{Keywords}

Cosmetics, Side Effects, Hydroquinone, Skin Lightening

\footnotetext{
*Corresponding author.
}

How to cite this paper: Osman, H.M., Shayoub, M.E., Ahmed, M.M.E. and Babiker, E.M. (2015) Assessment of Using Cosmetics Containing Hydroquinone among Sudanese Women. Journal of Cosmetics, Dermatological Sciences and Applications, 5, 73-77. http://dx.doi.org/10.4236/jcdsa.2015.52009 


\section{Introduction}

Cosmetics (colloquially known as makeup) are care substances used to enhance the appearance or odor of the human body. They are generally mixtures of chemical compounds, some being derived from natural sources but many are synthetic compounds [1].

Of these synthetic chemical products, hydroquinone-containing products are currently used for cosmetic purposes. Hydroquinone is an aromatic compound derived from phenol. It is a crystalline powder. It is well-known for its antioxidant properties and is widely used as a stabilizer in the coating industry. Hydroquinone pure substance may cause severe damages to human health: it is an eye irritant and a possible skin sensitizer and it is harmful if swallowed. It is suspected to cause genetic defects and cancer [2]. Hydroquinone is also very toxic to aquatic life. The pure substance is used in a large number of industrial and professional applications. Hydroquinone is benzene-1,4-diol belonging to the aromatic organic phenol compounds having the chemical formula $\mathrm{C}_{6} \mathrm{H}_{4}(\mathrm{OH})_{2}$. It is one of the most effective inhibitors of melanogenesis and is widely used for the treatment of melanosis and other related disorders of hyper-pigmentation. Hydroquinone is also used in many skin bleaching creams and lotions [3].

Some concerns about hydroquinone safety on skin have been expressed; the previous study found when hydroquinone comes to topical application indicates negative reactions which are minor or other is due to using extremely high concentrations of it [4]. Moreover, the World Health Organization [5] reported that the long term use of this chemical would lead to liver and kidneys failure. In addition to this, skin cancer risk probably may develop as melanin synthesis responsible for its protection against ultraviolet radiation would be inhibited by this chemical.

The present work is aimed to assess awareness of Sudanese women about the risks of hydroquinone and its side effects.

\section{Materials and Methods}

Data were collected in Khartoum city during April and May of 2014 via questionnaire format designed to elicit the picture of using hydroquinone by different age groups of Sudanese women as this chemical is abundant in cosmetic places and easy to buy in low prices from local market. The format included information about the age, Job and social status of participant as well as time of using, duration and dosage of cosmetic. Participants involved in the study were 69 volunteered women where prior consent from each was ensured and those did not use hydroquinone-containing cosmetic was rejected. Data collected was analyzed and presented following conventional descriptive statistical methods.

\section{Results}

The results of percentage of those using the cosmetic according to age distribution of participants, their marital status and the time they applied the creams during the day are shown in Table 1.

The results revealed that cosmetics were highly used by women aged between 20 and 29 years (78.3\%) followed by the other two groups having nearly equal percentages; $11.6 \%$ for those aged between 30 and 39 years and $10.1 \%$ for those aged 40 - 50 years. According to marital status, the increasing prevalence of using cosmetics was in this order; $69.6 \%, 26.1 \%$ and $4.3 \%$ for the single, married and divorced women, respectively while regarding the time of the day it was in this order; $81.2 \%, 15.9$ and $2.9 \%$ during evening, afternoon and in the morning, respectively.

The results regarding distribution of the prevalence of using cosmetics among women according to their occupation and duration of use as well as purpose of using the cream are shown in Table 2.

The results showed that a high prevalence of use was confined to students (56.5\%), followed equally by employee (17.4\%) and housewife (17.4\%) while $8.6 \%$ was shown by unclassified women. For the duration of using cosmetics, the distribution of prevalence was in this sequence; (39.1\%), 36.23\%, 17.4\% and $7.2 \%$ for extending using it for months, weeks, years, and only days, respectively. In the meantime, the results showed a high percentages of women (65.2\%) was using cosmetics containing hydroquinone (65.2\%) for skin lightening followed by $20.3 \%$ to eliminate acne, $10.1 \%$ for skin lightening plus to eliminate acne and $4.3 \%$ to eliminate freckles only.

The results of percentage of women aware by saying (Yes or No) regarding different aspects related to cosmetics are shown in Table 3. The results showed a high percentage of women (94.2\%) received the cream over 
Table 1. Distribution of prevalence of using cosmetic according to age group, marital status and dose during a day.

\begin{tabular}{ccccc}
\hline & \multicolumn{3}{c}{ Total } \\
\hline \multirow{2}{*}{ Age group } & $20-29$ years & $30-39$ years & $40-50$ years & $69(100 \%)$ \\
Marital status & $54(78.3 \%)$ & $8(11.6 \%)$ & $7(10.1 \%)$ & $69(100 \%)$ \\
& Single & Married & $3(4.3 \%)$ & $69(100 \%)$ \\
\hline
\end{tabular}

Table 2. Distribution of prevalence of using cosmetic according to occupation, duration and purpose of using hydroquinone.

\begin{tabular}{|c|c|c|c|c|c|}
\hline \multirow[b]{2}{*}{ Occupation } & \multicolumn{4}{|c|}{ Prevalence (\%) } & \multirow{2}{*}{$\begin{array}{c}\text { Total } \\
69(100 \%)\end{array}$} \\
\hline & $\begin{array}{c}\text { Students } \\
39(56.5 \%)\end{array}$ & $\begin{array}{c}\text { Employee } \\
12(17.4 \%)\end{array}$ & $\begin{array}{l}\text { Housewife } \\
12(17.4 \%)\end{array}$ & $\begin{array}{c}\text { Other } \\
6(8.6 \%)\end{array}$ & \\
\hline Duration & $\begin{array}{c}\text { One week } \\
5(7.2 \%)\end{array}$ & $\begin{array}{c}\text { Weeks } \\
25 \text { (36.2\%) }\end{array}$ & $\begin{array}{c}\text { Months } \\
27 \text { (39.1\%) }\end{array}$ & $\begin{array}{c}\text { Years } \\
12(17.4 \%)\end{array}$ & $69(100 \%)$ \\
\hline Purpose & $\begin{array}{c}\text { Elimination } \\
\text { of acne } \\
14(20.3 \%)\end{array}$ & $\begin{array}{c}\text { Elimination } \\
\text { of freckles } \\
3(4.3 \%)\end{array}$ & $\begin{array}{c}\text { Skin } \\
\text { lightening } \\
45(65.2 \%)\end{array}$ & $\begin{array}{c}\text { Skin lightening + } \\
\text { elimination of acne } \\
7(10.1 \%)\end{array}$ & 69 (100\%) \\
\hline
\end{tabular}

Table 3. Percentage of (yes/no) answers of participants to questions regarding prescription, nature and risk, side effects, regularity of use and if more than one type of hydroquinone was used.

\begin{tabular}{cccc}
\hline Enquiry & Yes & No & Total \\
\hline If had been prescribed & $4(5.8 \%)$ & $65(94.2 \%)$ & $69(100 \%)$ \\
If aware of it nature and risk & $10(14.5 \%)$ & $59(85.5 \%)$ & $69(100 \%)$ \\
If side effects being induced & $34(49.3 \%)$ & $35(\% 50.7)$ & $69(100 \%)$ \\
If more than one type being used & $38(55.1 \%)$ & $31(44.9 \%)$ & $69(100 \%)$ \\
If being used regularly & $23(33.3 \%)$ & $46(66.7 \%)$ & $69(100 \%)$ \\
\hline
\end{tabular}

the counter without a prescription by medical doctor and (85.5\%) did not know its nature and risks on human health. Moreover, (50.7\%) admitted to have side effects awareness and (44.9\%) used more than one type of cosmetics and (33.3\%) used it regularly.

However, the consequences of using cosmetics informed by women are shown in Table 4. Of these women $50.7 \%$ showed no signs or symptoms due to this cosmetics while those showing signs were in this increasing order: redness (17.4\%), pigmentations (13.0), redness plus grain (7.2\%), grain (7.2\%) and exfoliation (4.3\%).

On the other hand, the percentages of different cosmetics containing hydroquinone that were used by women of this study are shown in Table 5. According to the increased percentage of use, the arrangement of these chemicals will be as follows: amalico (34.8\%), lucocid (14.5\%), tritospot (11.6\%), avalone (7.2\%), skinsucces (7.2\%), baby face (5.8\%), suffix (4.3\%), Divacream (4.3\%), pure hydroquinone (2.9\%), oranvate (1.4\%), eldoquin forte (1.4\%), melanofree (1.4\%), civiiclemon (1.4\%) and orange (1.4\%).

\section{Discussion}

Although, a considerable number of Sudanese women are using hydroquinone to brighten their skin but only 69 participants agreed to take part in this study. This lack of cooperation of some cosmetics users probably based on their personal experience that the information given would not be used for the purpose of study or some of them might feel shy to give this information. However, despite the fact that the sample size of this study was not as large as usually would be preferred in such a kind of study, but still could give insight as to the awareness of subjects towards using cosmetics containing hydroquinone. It was evident that, a considerable proportion of Sudanese women, particularly, young unmarried students indulged in these chemicals and their time at the even- 
Table 4. Number and percentage (\%) of women showing different symptoms induced by hydroquinone.

\begin{tabular}{ccc}
\hline Symptoms & No & Percent (\%) \\
\hline No signs & 35 & 50.7 \\
Redness & 12 & 17.4 \\
Grain & 5 & 7.2 \\
Exfoliation & 3 & 4.3 \\
Pigmentations & 9 & 13.0 \\
Redness + grain & 5 & 7.2 \\
Total & 69 & 100 \\
\hline
\end{tabular}

Table 5. Percentage of distribution of using different hydroquinone by Sudanese women.

\begin{tabular}{ccc}
\hline The compound used & Frequency & Percent (\%) \\
\hline Amalico & 24 & 34.8 \\
Avalone & 5 & 7.2 \\
Baby face & 4 & 5.8 \\
Tritospot & 8 & 11.6 \\
Suffix & 3 & 4.3 \\
Oranvate & 1 & 1.4 \\
Lucocid & 10 & 14.5 \\
Eldoquin forte & 1 & 1.4 \\
Divacream & 3 & 4.3 \\
Skinsucces & 5 & 7.2 \\
pure hydroquinone & 2 & 2.9 \\
Melanofree & 1 & 1.4 \\
Civiiclemon & 1 & 1.4 \\
Orange & 1 & 1.4 \\
Total & 69 & 100 \\
\hline
\end{tabular}

ings as most of the Sudanese remained at home until the next day. Perhaps, the slightly high percentage of women who used chemicals for months rather than those for days or weeks or years might be due to achieving by lasting this duration the most preferred purpose of using the chemical which was the skin lightening.

The results of this study, unfortunately, revealed that the subjects were unaware of the hazards that might develop by exposing their skin to these chemicals. This claim can be strengthened by the fact that a high percentage of women (94.2\%) neither consulted a medical doctor nor appreciating the hazards of these chemicals (85.5\%). Moreover, they were using a wide range of cosmetics containing hydroquinone and perhaps ignored the appearance of the side effects which might lead to serious skin problems.

In this context, it had been reported that hydroquinone when applied at levels higher than the recommended could result in thinning of the skin, irreversible white patches where the melanin producing cells would have been destroyed and could act as an eye, nose, skin and mucous membrane, gastro-intestinal and respiratory irritant [6]. Also, increase in skin temperature could result in an increased flow rate of these compounds [7], hence that might lead to exposing skin to side effects as a result of these difficult environmental conditions. Other than these, hydroquinone was reported unsafe for use because of increasing the risk of developing skin cancers from 
sun exposure since it makes one's skin more sensitive to the sun’s damaging ultraviolet rays. Therefore, it had been banned in some countries like France because of fears of cancer risk [8]. Together with this, hydroquinone was found to be responsible for incurred nephropathy and renal cell proliferation [5].

It is obvious that most synthetic agents were aimed to rate limiting enzyme of melanogenesis tyrosinase, and to bring about alternative hypopigmenting mechanisms [9] but on application they were abused and the customers were not complying with instructions enclosed with product package. It had been noticed that on applying a small amount of this medicine to an area of unbroken skin, this area of application must be checked within 24 hours for any serious side effects. If there was any itching, redness, puffy or blistering, the use of product should be stopped and the doctor to be contacted but with just mild redness the treatment with the product may continue.

The problem with Sudanese women was that their regular use of hydroquinone for cosmetic purposes. This regularity in using perhaps was enhanced as these products were available almost in most local markets and sold in small fractions so as to be bought with low prices. Added to this, the chemicals were brought out from their origin containers without any consideration to optimal storage conditions and that might lead to changing these chemical to harmful compounds especially when heated by the very hot weather in Sudan. Moreover, in some instances the containers did not carry labeling and this may lead to bad handling. The expected hazards of such bad handling could be inspired from previous reports advising that these products must be placed at optimal room temperature, away from light and moisture [6].

\section{Conclusion}

The present study concluded that the awareness of customers of hydroquinone should be raised via health education and its handling should be banned except for those with authenticated license.

\section{References}

[1] Gunter, S., SvenGohla, J., Whaltrand, K., Uwe Schonrock, H., Schmidt, L., Annegret, K., Xenia, P., Wolfgang, P., Hellmut, I. and Walter, D. (2005) Skin Cosmetics, in Ullmann's Encyclopedia of Industrial Chemistry. Willey VCH, Weinheim, 280-285.

[2] Priyanka, M., Ketki, D. and Hyacinth, H. (2013) Cytotoxic Effects of Benzene Metabolites on Human Sperm Function: An in Vitro Study. ISRN Toxicology, 2013, Article ID: 397524, 6pp.

[3] Karamagi, E., Owino, E. and Katabira, E. (2001) Hydroquinone Neuropathy Following Use of Skin Bleaching Creams: Case Report. East African Medical Journal, 78, 223-224. http://dx.doi.org/10.4314/eamj.v78i4.9069

[4] Us Food and Drug Administration (USFDA) (1992) FDA’s Cosmetics Handbook Washington DC, US Department of Health and Human Services, Public Health Service. Food and Drug Administration, 2, 21-23.

[5] WHO. IPCS International Programme on Chemical Safety (1996) Health and Safety. Hydroquinone, Health and Safety Guide, No. 101, Rom.

[6] Oyedeji, F., Hassan, G. and Adeleke, B. (2011) Hydroquinone and Heavy Metals Levels in Cosmetics Marketed in Nigeria. Trends in Applied Sciences Research, 6, 622-639. http://dx.doi.org/10.3923/tasr.2011.622.639

[7] Vikas, B., Rajni, K., Arun, K. and Dinesh, K. (2014) A Novel Approach for Drug Delivery System. World Journal of Pharmaceutical Research, 3, 318-334.

[8] Belezal, S. (2012) The Timing of Pigmentation Lightening in European. British Journal of Dermatology, 120, $229-238$.

[9] Lei, T., Virador, V., Vieira, W. and Hearing, V. (2002) A Melanocyte-Keratinocyte Coculture Model to Assess Regulators of Pigmentation in Vitro. Analytical Biochemistry, 305, 260-268. http://dx.doi.org/10.1006/abio.2002.5665 